\title{
Exposure to solvents in a synthetic leather manufacturing plant
}

Received: 14 June 1999 / Accepted: 20 November 1999

\begin{abstract}
The objective of this study was to evaluate the exposure of synthetic leather workers to dimethylformamide (DMF), epichlorohydrin (ECH) and toluene, in a manufacturing plant. The correlation between biological and environmental monitoring for DMF was also investigated. Environmental monitoring of the three solvents included personal and area sampling based on time of day (morning and afternoon). Urine samples were taken at the end of the shift and urinary $\mathrm{N}$-methylformamide (NMF) was then used to biologically monitor DMF levels. Results for solvent concentrations based on air sampling were considerably higher in area than in personal sampling. Of 41 area samples, 15 $(36.6 \%)$ and five $(12.2 \%)$ exceeded permissible exposure levels for DMF and $\mathrm{ECH}$, respectively, compared with $22(28.6 \%)$ and three $(3.9 \%)$ based on 77 personal samples. Overall, urinary NMF concentrations were lower than the Biological Exposure Index (BEI) suggested by the American Conference of Governmental Industrial Hygienists (ACGIH). A significant correlation $(r=0.32 ; P<0.05)$ was found between environmental and biological monitoring. Even though urinary NMF concentration was within permissible levels for Taiwan, the authors recommend that immediate measures be taken to decrease DMF and ECH concentrations in synthetic leather manufacturing plants.
\end{abstract}

H. W. Kuo $(\varangle) \cdot$ Y. S. Huang

Institute of Environmental Health, China Medical College, 91, Hsueh-Shin Road, Taichung, Taiwan

e-mail:wukuo@mail.cmc.edu.tw

Tel.: +886-4-2054076; Fax: +886-4-2019901

J. C. Lo $\cdot$ M. J. Chang Wu

College of Medicine, Chang Gung University, Taoyuan, Taiwan

T. J. Cheng

Graduate Institute of Occupational Medicine and Industrial

Hygiene, College of Public Health, Taipei, Taiwan

\section{Introduction}

The plant investigated in this study was built more than 20 years ago, currently employs 562 workers and is one of the leading manufacturers of polyurethane in Taiwan. During the past year, an industrial health consulting company conducted regular monitoring of solvent concentrations (including dimethylformamide (DMF), epichlorohydrin (ECH), methylethylketone (MEK), and toluene) and declared the plant to be in accordance with permissible levels. However, this conflicted with results from medical examinations that tested for alanine aminotransferase (ALT) levels: one-sixth of the manufacturing workforce was found to have liver function abnormalities. Common symptoms reported by employees included fatigue, memory lapses, abdominal pains, headaches, and eye or skin irritations. Consequently, plant managers doubted the accuracy of the monitoring results and requested the authors to measure solvent exposure concentrations based on area and personal sampling. Results from this study were then used as a reference for the maintenance of worker health by the monitoring and controlling of solvent concentrations.

Dimethylformamide (CAS no. 106-89-8) is widely used as a solvent, especially for resins and polar polymers, and as a booster or co-solvent in applications such as protective coatings, adhesives, films and printing inks. Studies (Flemming et al. 1990, Redlich et al. 1990) have shown that acute or chronic exposure to DMF affects the liver and upper gastrointestinal tract. In 1991, Wang et al. investigated the prevalence of liver damage among synthetic leather workers exposed to DMF. Wang concluded that based on the prevalence of abnormal liver function, an interactive effect existed between hepatitis B serum antigen (HBsAg) carrier status and DMF exposure concentrations. He also reported a significant link between elevated creatine phosphokinase (CPK) levels and DMF exposure. A cross-sectional study by Fiorito et al. (1997) of the prevalence of chronic liver dysfunc- 
tion among 75 synthetic leather factory employees showed that DMF exposure can cause liver disease even if air threshold limit values (TLVs) are respected. Liver abnormalities were due to accidental contact with liquid DMF that significantly increased DMF uptake.

Epichlorohydrin (CAS no. 68-12-2) is a major raw material in the manufacture of epoxy and phenoxy resins, and as a solvent in the rubber and paper industries. Contact with $\mathrm{ECH}$ in its liquid or vapor form can readily lead to irritation of the eyes, skin, and respiratory tract. Also, systemic absorption may occur after contact of ECH with the respiratory epithelium or skin. Studies on rats by Laskin et al. (1980) and Wester et al. (1985) found that tumors (squamous cell carcinoma and papilloma) developed in the nasal cavities following exposure to $100 \mathrm{ppm}$ of $\mathrm{ECH}$ for $6 \mathrm{~h} /$ day for 30 days. These studies were conducted over the lifetime of the rats. Until now, few studies (Sram et al. 1981, Sram et al.1983) have found a clear correlation between longterm exposure to $\mathrm{ECH}$ and adverse physical effects in humans, mainly due to inadequate evaluation of $\mathrm{ECH}$ concentrations in area and personal sampling. Because the synthetic leather manufacturing process is relatively complicated, workers at different workstations are exposed to varying concentrations and types of solvents.

The objective of this study was to evaluate exposure of personnel to DMF, ECH and toluene in a synthetic leather manufacturing plant. The correlation between biological and environmental monitoring for DMF was also investigated. Environmental monitoring of the three solvents included personal and area sampling based on time of day (morning and afternoon). The results of this study may be used as a reference by synthetic leather manufacturers for maintaining worker health.

\section{Materials and methods}

The synthetic leather manufacturing plant which was studied has been in operation for over 20 years and employed a total of 562 workers. The current investigation was concerned solely with the wet process, which requires a relatively large amount of DMF and lesser quantities of other solvents such as $\mathrm{ECH}$ and toluene. Ethyl acetate, methylethylketone (MEK), butanone, acetone and methylene dichloride are also used, but these were not included in the current study because in the authors' previous investigation it was found that the concentrations were very low (unpublished). Solvents and coloring agents are mixed with polyurethane components or with other resins in a mixer, after which they are pumped onto fabric which is then dipped into water. For the purposes of the present study, an industrial hygienist divided the plant into three workstations, based on the amount of solvents used in the manufacturing processes. Workstation I had high DMF levels and very low ECH. Workstation II had moderate levels of both DMF and $\mathrm{ECH}$. Workstation III had high levels of ECH and low levels of DMF. (Details of the manufacturing processes can be found in the Results section.)

Workers' demographic data, medical history (including specific symptoms such as fatigue, memory lapse, abdominal pain, headaches and eye/skin irritation), work experience and their perception of their own solvent exposure levels (subjectively classified into three levels: none/low, moderate, high) were determined by questionnaire. The correlation between perception of personal exposure level and the actual exposure (measured by personal and area sampling) was evaluated. Air and personal sampling data were classified into three percentage groups $(<25 \%, 25-75 \%$ and $>75 \%)$.

\section{Environmental monitoring}

A walkthrough was conducted in order to understand worker scheduling and mechanical operations, and to use a detector to make rough estimates of solvent concentrations. Both area and personal sampling tasks were performed. A total of 21 area sampling points were selected throughout the plant, based on proximity to sources of solvent emissions. Sampling time ranged from 30 to $180 \mathrm{~min}$. Fortyfive workers from the three workstations were selected at random for personal sampling. Each had a sampler attached to the collar of the shirt, and sampling was performed for a period of $90 \mathrm{~min}$ each morning and afternoon (180 min total). Calculations were made based on the time-weighted average (TWA). The analytical methods used were modified versions of those of previous studies (Imbriani et al. 1986, Wang et al. 1991, Sakai et al.1995). Airborne samples were collected after 6 to 361 of air had passed through the charcoal tubes which were then capped, sealed with paraffin, stored at $4{ }^{\circ} \mathrm{C}$ and analyzed within 2 weeks. Charcoal was desorbed using $\mathrm{CS}_{2}$ and acetone (in proportion of 3:2 by volume). Xylene, an internal standard, was then added to the desorbed solution. GC/FID was used to analyze the solvents with a fused silica WCOT column (DB5-30 $\mathrm{m} \times$ $0.53 \mathrm{~mm}$ ID). Injector and detector temperatures were set at $200{ }^{\circ} \mathrm{C}$ and $250^{\circ} \mathrm{C}$, respectively. The initial temperature of the oven was held at $50{ }^{\circ} \mathrm{C}$ for $6 \mathrm{~min}$, and increased by $20^{\circ} \mathrm{C}$ per min until it reached $90{ }^{\circ} \mathrm{C}$ where it was held for $1 \mathrm{~min}$. Quality control for the calibration curve was performed by the calculation of the correlation coefficient $(>0.995)$ and the relative prediction deviation $(<10 \%)$. The reproducibility (CV) of the three solvents (at low, medium, and high concentrations) ranged from $0.9 \%$ to $5.7 \%$. Average desorption efficiency for DMF and ECH (at concentrations of $0.5,1$, and $2 \times \mathrm{TLV}$ ) were $76.9 \%$ and $112.4 \%$, respectively. Based on an injection volume of $1 \mu \mathrm{l}$, detection limits for DMF, ECH, and toluene were $0.86 \mathrm{ng}, 0.74 \mathrm{ng}$, and $0.41 \mathrm{ng}$, respectively.

\section{Biological monitoring}

In order to investigate the consistency over time of urinary $\mathrm{N}$-methylformamide (NMF) levels, the investigators took two urine samples, 1 month apart. Both samples were taken at the end of the shift and stored at $4{ }^{\circ} \mathrm{C}$ for 2 weeks. As part of pretreatment, centrifugation was set at $10,000 \mathrm{~g}$ for $20 \mathrm{~min}$, and urine supernatant was extracted. An internal standard ( $N$-methylacetamide) was added to the samples and standard. This mixture was centrifuged at $10,000 \mathrm{~g}$ for $10 \mathrm{~min}$. Again, a supernatant was collected from the mixture and analyzed using GC-NPD fused silica WCOT (DB WAX $30 \mathrm{~m} \times 0.25 \mathrm{~mm}$ ID). The injector and detector temperatures were set at $300{ }^{\circ} \mathrm{C}$ and $250^{\circ} \mathrm{C}$, respectively. The initial oven temperature was held at $110^{\circ} \mathrm{C}$ for $6 \mathrm{~min}$ and increased by $5^{\circ} \mathrm{C}$ per min until it reached $190^{\circ} \mathrm{C}$ where it was maintained for $1 \mathrm{~min}$. The oven temperature was then increased by $10^{\circ} \mathrm{C}$ per min to $200{ }^{\circ} \mathrm{C}$ where it was kept for $1 \mathrm{~min}$. Five kinds of NMF from $0.66 \mu \mathrm{g}$ to $16.5 \mu \mathrm{g}$ were spiked on the urine samples, and the recovery rates were determined and ranged from $97.95 \%$ to $113.86 \%$. The CV of NMF and $N$-methylacetamide (NMA) were $0.51 \%$ and $0.80 \%$. Based on injection volume of $1 \mu \mathrm{l}$, the detection limit of NMF was found to be $0.17 \mathrm{ng}$.

\section{Statistical analysis}

The SAS/PC + 6.04 package (1986) was used to analyze the results. Mean and standard deviations were used to describe the results of the air and personal sampling data. The kappa value showed the correlation between worker perception of personal exposure and the actual solvent exposure levels. Analysis of variance (ANOVA) was used to compare the three groups of DMF exposure to biological monitoring. Pearson's correlation was used to show the relationship between environmental and biological monitoring. 


\section{Results}

Based on morning and afternoon sampling, ECH was detected only in Workstation III. Table 1 shows the results of area sampling for $\mathrm{ECH}, \mathrm{DMF}$, and toluene in the three workstations. In Workstation I, the highest and second highest concentrations of DMF were found in the blending and post-treatment areas. In the morning and afternoon sampling, concentration averages were $10.31 \mathrm{mg} / \mathrm{m}^{3}$ and $13.36 \mathrm{mg} / \mathrm{m}^{3}$ for DMF and $18.6 \mathrm{mg} /$ $\mathrm{m}^{3}$ and $27.9 \mathrm{mg} / \mathrm{m}^{3}$ for toluene. DMF and toluene concentrations were lower in Workstation II than in Workstation I and lowest in Workstation III. In Workstation II the highest concentration of DMF $\left(28.67 \mathrm{mg} / \mathrm{m}^{3}\right)$ based on morning sampling was found near the assembly machine. In Workstation III, the highest concentration of ECH $\left(15.09 \mathrm{mg} / \mathrm{m}^{3}\right)$ from morning sampling was found in the chemical analysis laboratory. In comparison, solvent concentrations from morning and afternoon sampling were inconsistent.

Based on personal sampling, ECH was detected in relatively high concentrations in Workstation III, relatively low concentrations in Workstation II, and not at all in Workstation I. Table 2 shows ECH, DMF, and toluene concentrations from personal sampling. On the basis of morning sampling in Workstation I, DMF concentrations were highest near the dry coating and dry PU-coating machines. Average DMF concentrations from morning and afternoon sampling in Workstation I were $45.21 \mathrm{mg} / \mathrm{m}^{3}$ (range: non-detectable (ND)-360.45) and $8.87 \mathrm{mg} / \mathrm{m}^{3}$ (range: ND-25.65), respectively. For morning sampling results, DMF concentrations in Workstation II were lower than those in Workstation I. Average DMF concentrations for morning and afternoon sampling in Workstation II were $37.8 \mathrm{mg} / \mathrm{m}^{3}$ (range: ND-94.06) and $4.61 \mathrm{mg} / \mathrm{m}^{3}$ (range: ND-16.29). In Workstation III, ECH concentrations for morning and afternoon sampling were highest in the technical area, $20.0 \mathrm{mg} / \mathrm{m}^{3}$ and $8.5 \mathrm{mg} / \mathrm{m}^{3}$. DMF concentrations based on morning and afternoon sampling were considerably lower in Workstation III, averaging $8.4 \mathrm{mg} / \mathrm{m}^{3}$ and $13.0 \mathrm{mg} / \mathrm{m}^{3}$.

Consistency between workers' subjective perception of solvent exposure levels and sampling results was significantly low. Table 3 compares perception of DMF concentrations with area and personal sampling results. Most often, operators perceived levels to be lower than sampling results showed. The only consistency between sampling results and worker perception was by those who reported high exposure levels. Overall, results showed that job location and workers' perceptions of their own exposure were often inconsistent with the actual exposure levels.

Area and personal sampling results were consistent after the concentrations were divided into three levels: low $\left(<1.56 \mathrm{mg} / \mathrm{m}^{3}\right)$, middle $\left(1.56-8.69 \mathrm{mg} / \mathrm{m}^{3}\right)$, and high $\left(>8.69 \mathrm{mg} / \mathrm{m}^{3}\right.$. Table 4 shows environmental and biological monitoring of DMF exposure concentrations)

Table 1 Concentrations $\left(\mathrm{mg} / \mathrm{m}^{3}\right.$; mean $\left.\pm \mathrm{SD}\right)$ of $\mathrm{ECH}$, DMF and toluene based on area sampling in different workstations in the morning and afternoon (ND non-detectable)

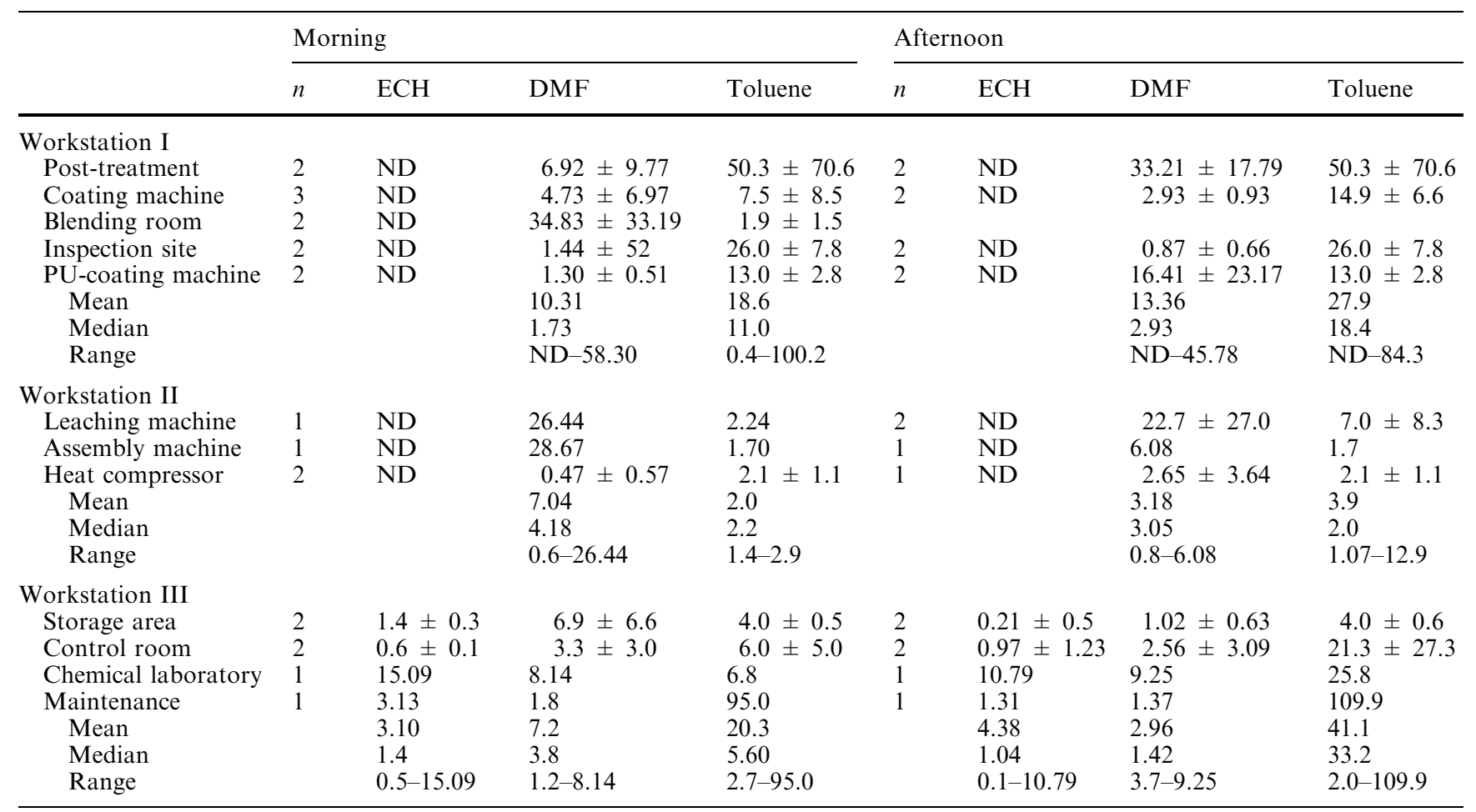


Table 2 Concentrations $\left(\mathrm{mg} / \mathrm{m}^{3}\right.$; mean $\left.\pm \mathrm{SD}\right)$ of $\mathrm{ECH}$, DMF and toluene based on personal sampling in different workstations in the morning and afternoon (ND non-detectable)

\begin{tabular}{|c|c|c|c|c|c|c|c|c|}
\hline & \multicolumn{4}{|c|}{ Morning } & \multicolumn{4}{|c|}{ Afternoon } \\
\hline Administration area & 2 & ND & $3.74 \pm 5.23$ & $0.7 \pm 0.9$ & 2 & ND & $0.5 \pm 0.5$ & $0.5 \pm 0.6$ \\
\hline Inspection site & 1 & ND & 1.78 & ND & & & & \\
\hline Mixing room & 1 & ND & $6.19 \pm 6.38$ & $114.3 \pm 161.5$ & 2 & ND & $7.19 \pm 1015$ & $0.2 \pm 0.2$ \\
\hline Dry PU-coating machine & 2 & ND & $50.30 \pm 41.44$ & $207.4 \pm 178.0$ & 2 & ND & $10.24 \pm 6.20$ & $102.5 \pm 61.8$ \\
\hline Median & & & 10.26 & 175.4 & & & 4.01 & 8.9 \\
\hline Range & & & ND-360.45 & ND-333.3 & & & ND-25.65 & ND-146.2 \\
\hline \multicolumn{9}{|l|}{ Workstation II } \\
\hline Recycling area & 2 & $1.9 \pm 1.4$ & $0.2 \pm 0.1$ & $0.7 \pm 0.1$ & 3 & ND & $1.07 \pm 0.99$ & $5.4 \pm 3.4$ \\
\hline Leaching machine & 6 & $0.4 \pm 0.2$ & $51.7 \pm 7.7$ & $1.2 \pm 0.1$ & 5 & ND & $9.66 \pm 5.42$ & $8.3 \pm 1.1$ \\
\hline Maintenance & 1 & ND & 2.9 & 0.8 & 1 & ND & 2.5 & 1.0 \\
\hline Range & & ND- -0.6 & ND-94.06 & ND-4.4 & & & ND-16.29 & ND-9.9 \\
\hline \multicolumn{9}{|l|}{ Workstation III } \\
\hline Operator & 3 & $0.3 \pm 0.3$ & $2.5 \pm 1.7$ & $1.7 \pm 0.9$ & 4 & $0.8 \pm 0.8$ & $10.6 \pm 9.9$ & $9.4 \pm 7.3$ \\
\hline Technical room & 4 & $20.0 \pm 29.0$ & $14.4 \pm 16.6$ & $3.0 \pm 1.4$ & 3 & $8.5 \pm 14.2$ & $9.9 \pm 5.9$ & $8.7 \pm 1.2$ \\
\hline Maintenance division & 3 & $3.6 \pm 3.5$ & $19.5 \pm 31.6$ & $2.0 \pm 0.2$ & 3 & $4.3 \pm 5.6$ & $16.9 \pm 10.1$ & $11.8 \pm 5.0$ \\
\hline Factory services room & 4 & $23.1 \pm 11.3$ & $8.4 \pm 8.7$ & $1.4 \pm 0.4$ & 4 & $0.2 \pm 0.2$ & $3.5 \pm 2.8$ & $7.9 \pm 6.2$ \\
\hline Mean & & 12.5 & 8.4 & 2.0 & & 4.2 & 13.0 & 9.7 \\
\hline Median & & 7.5 & 3.0 & 1.8 & & 0.8 & 9.9 & 8.1 \\
\hline Range & & ND-63.0 & ND-33.2 & ND -4.5 & & ND-24.9 & ND -41.0 & ND-19.4 \\
\hline
\end{tabular}

Table 3 Consistency between workers' personal perceptions of DMF exposure and field sampling

\begin{tabular}{|c|c|c|c|c|c|c|}
\hline & \multicolumn{3}{|c|}{ Area sampling } & \multicolumn{3}{|c|}{ Personal sampling } \\
\hline & Non/low & Medium & High & Non/low & Medium & High \\
\hline \multicolumn{7}{|c|}{ Personal perception } \\
\hline Non/low & 9 & 18 & 8 & 12 & 11 & 12 \\
\hline Medium & 0 & 0 & 6 & 0 & 6 & 0 \\
\hline High & 0 & 1 & 7 & 0 & 4 & 4 \\
\hline Kappa value & & 0.10 & & & 0.28 & \\
\hline
\end{tabular}

Table 4 A comparison of DMF exposure levels (mean $\pm \mathrm{SD}$ ) based on environmental and biological sampling

\begin{tabular}{lllll}
\hline \multicolumn{5}{l}{ DMF exposure } \\
\cline { 2 - 5 } & $\begin{array}{l}\text { Low } \\
(n=15)\end{array}$ & $\begin{array}{l}\text { Medium } \\
(n=24)\end{array}$ & $\begin{array}{l}\text { High } \\
(n=10)\end{array}$ & $P$ value $^{\mathrm{a}}$ \\
\hline Area sampling $\left(\mathrm{mg} / \mathrm{m}^{3}\right)$ & $1.19 \pm 0.31 \mathrm{a}$ & $6.28 \pm 2.56$ & $27.64 \pm 9.99$ & $<0.01$ \\
Personal sampling $\left(\mathrm{mg} / \mathrm{m}^{3}\right)$ & $0.84 \pm 0.81$ & $3.99 \pm 3.92$ & $27.01 \pm 56.89$ & 0.03 \\
NMF concentration (first sampling) & $2.05 \pm 2.02$ & $0.93 \pm 0.72$ & $1.46 \pm 0.85$ & 0.16 \\
NMF concentration (second sampling) & $1.39 \pm 1.40$ & $1.17 \pm 0.91$ & $0.85 \pm 1.12$ & 0.5 \\
\hline
\end{tabular}

${ }^{\text {a }}$ Calculated on the basis of a comparison of the three groups
However, NMF levels in urine samples were inconsistent with results from area and personal sampling. Based on area sampling for low DMF exposure, NMF concentrations were relatively high in the first and second urine samples, compared with those from medium and high DMF exposures. The correlation coefficient for the two urine samples based on NMF concentrations was 0.51 $(P<0.01)$.

\section{Discussion}

As the result of a preliminary walkthrough and consultations with an industrial hygienist, the synthetic leather manufacturing process was divided into three major workstations with each workstation further classified into individual processes. Personal and area sampling 
results revealed that exposure concentrations varied considerably in terms of work process and time of day. Since ECH was used only in Workstation III, its concentrations were highest there. Both toluene and DMF were found in all three workstations. The air sampling results showed that exposure concentrations were correlated to the use of a particular solvent in a manufacturing process. Dry coating machine operators (Workstation I) were exposed to the highest concentrations of DMF and toluene. This was due to solvents readily vaporizing from the coating machine, which reached temperatures of 160 to $180^{\circ} \mathrm{C}$, and a lack of effective ventilation. Overall, for each of the three solvents, the results from area sampling were different from those from personal sampling. One of the reasons for this discrepancy may be because the area sampling pumps were in a fixed location near the source of the solvents, but workers were free to move about their area of the workstation. Also, semi-automation allowed some people to remain in operating rooms, isolated from the machines. By spreading vapor, electric fans were responsible for the fact that solvents were detected in areas in which they were not used. There were many environmental factors which may have affected the environmental monitoring results, such as location with regard to fans (areas downwind of the fans had significantly higher exposure concentrations than areas upwind), volume of air in the plant, temperature and humidity. Since biological monitoring represents exposure levels from many sources, such monitoring is better able to portray the true uptake of solvents than is air sampling, which is readily influenced by other factors and does not take into account the fact that solvents may be readily absorbed through the skin. Our results showed that there was only a slight correlation between environmental and biological monitoring $(r=0.32)$. However, there was a high degree of consistency over time. The correlation between urinary NMF in the two urine samples (taken a month apart) was 0.51.

In Taiwan, permissible levels for DMF and ECH are $29.9 \mathrm{mg} / \mathrm{m}^{3}$ and $7.5 \mathrm{mg} / \mathrm{m}^{3}$, respectively. Based on 41 area samples collected from the three workstations, 15 $(36.6 \%)$ and five $(12.2 \%)$ exceeded permissible levels for DMF and ECH, respectively. Of 77 personal samples, 22 $(28.6 \%)$ and $3(3.9 \%)$ exceeded permissible levels for $\mathrm{DMF}$ and $\mathrm{ECH}$. The results from the independent consulting company showed that DMF concentration in air was non-detectable in most samples. However, the current study found that a significantly higher percentage of samples exceeded permissible levels. The authors speculate that the large discrepancy between the results of the current study and those of the consulting company may be due to poor quality control methods employed by the consulting company, that meant that the percentage of samples exceeding permissible levels was very low. Because government regulations often require plants to make safety modifications in the workplace that are usually very expensive, it is possible that unsuspecting bias on the part of the consulting company may have influenced the study, since it is unlikely that the consultancy would have won future contracts if the plant was found to have hazardous levels of solvents.

Workers' perceptions of their own solvent exposure levels differed significantly from the findings from area and personal sampling, due to several factors, physical and environmental. In almost all cases, employees perceived their exposure levels to be none or low, in direct contrast to sampling results. Often workers had a false sense of security because they assumed that they were not being exposed unless they directly handled or worked with solvents. Also, because most operators had several years' experience in this plant, their sensitivity to solvent smell was reduced considerably, and workers in general considered only inhalation, and not dermal absorption, as a means of exposure. People were unaware of their exposure levels because few underwent physical examinations which could have alerted them to the environmental harm being done to their health. As a result, workers took little or no precaution against solvent exposure. Environmentally, although solvents may not have been used in certain processes, blowing fans readily spread the vapor throughout the open spaces in the plant and residues were carried on the intermediate product being handled by operators in separate processes.

In previous studies by Yonemoto and Suzukia (1980) and Pozzoli et al. (1981), a high correlation was found between exposure levels and urinary excretions of NMF and DMF, respectively. However, the correlation coefficient in the current study was considerably lower $(r=0.341)$. This may have been because the majority of workers in high-exposure areas worked in isolation, wore masks to reduce exposure through inhalation and usually stayed in the operation area for a short period of time only. Also, a significant percentage of workers were HBsAg carriers, a condition which increased mixedfunction oxidase enzyme action. Although metabolized in the liver, DMF probably requires the enzyme during demethylation to monomethylformamide (MMF). HBsAg carriers probably generate MMF more rapidly and in larger quantities (Wang et al. 1991). There may be an interactive effect between HBsAg and DMF that requires further research. According to Mraz and Mahova (1992), skin absorption of DMF vapor may represent $13-36 \%$ of its total uptake, and this percentage is likely to rise in the event of accidental skin contact with the liquid solvent. In biological monitoring, urinary NMF concentration is routinely used as an indicator of occupational exposure to DMF. Because the biological half-life of NMF in urine is relatively short (approximately $12 \mathrm{~h}$ ), the timing of urine sampling is very important and can affect the interpretation of the measurement. In 1995, Sakai et al. used NMF and $N$-acetyl- $S$ - $(N$-methylcarbamoyl) cysteine (AMCC) to biologically monitor workers exposed to DMF. Results showed that AMCC represented an index of the average exposure during several workdays, and may indicate an internal dose. However, NMF represents only an index 
of daily exposure. Sakai et al. (1995) found widely varying results for NMF over a period of 10 consecutive days, and urinary levels of NMF decreased to almost zero within $24 \mathrm{~h}$ of the beginning of the last exposure. The American Conference of Governmental Industrial Hygienists (ACGIH) proposed that urine samples be collected at the end of the work-shift, and recommended that the Biological Exposure Index (BEI) be set at $40 \mathrm{mg} / \mathrm{g}$ creatinine. At this level, no urine samples from workers investigated in the current study exceeded government limits. The apparent inconsistency of this finding with the air sampling results may be explained by the plant manager's requirement that all workers in high-exposure areas wear masks. Also, the excretion rate of NMF is faster than that of AMCC, so the timing of collection was a critical factor in urinary NMF concentrations. In addition, the plant is semi-automated, with operators often remaining in an enclosed room away from the source of the solvent. Individual characteristics, such as being HBsAg carriers, and alcohol consumption, can cause a more rapid conversion of DMF to NMF that results in an elevated cytochrome p-450 enzyme function (Wang et al. 1991). Confirmation of Wang's hypothesis requires further study.

Before the study by Rooij et al. in 1997, no urinary biomarker of exposure was available for assessment of human exposure to ECH. Rooij used 3-chloro-2hydroproplmercapturic acid (CHPMA) and x-chlorohydrin as biomarkers of occupational exposure to $\mathrm{ECH}$. A tentative BEI of $6 \mathrm{mmol} 3$-chloro-2-hydroxypropylmercapturic acid/mol creatinine for ECH during an $8 \mathrm{~h}$ work-shift was used. Taiwan currently has no standards for the biological monitoring of ECH exposure. The permissible level for airborne $\mathrm{ECH}$ in the workplace in Taiwan is presently set at $7.5 \mathrm{mg} / \mathrm{m}^{3}$, much higher than the TLV-TWA $\left(0.5 \mathrm{mg} / \mathrm{m}^{3}\right)$ proposed by ACGIH (1999). This value was set at such a low level because there is evidence to suggest that ECH is carcinogenic. The current Dutch $8 \mathrm{~h}$ time-weighted occupational exposure limit for humans is $3.75 \mathrm{mg} / \mathrm{m}^{3}$ [Ministry of Social Affairs (MSA) 1995)]. Based on these two limits, solvent exposure in several areas that were examined in the present investigation exceeded present limits. Sram et al. in 1981 found that workers exposed to $1 \mathrm{mg} / \mathrm{m}^{3}$ $\mathrm{ECH}$ for 2 years exhibited an increase in chromosomal aberrations of peripheral lymphocytes. In the current study, workers were investigated for chromosomal abnormalities (sister chromatid exchange), In another study by Cheng and the authors (1999), it was concluded that ECH exposure may be associated with genetic toxicity, and that DMF does not appear to be genotoxic.

In conclusion, we found that the environmental monitoring results varied widely based on timing and location of measurements. Of 41 area samples, 15 $(36.6 \%)$ and five $(12.2 \%)$ were found to be in excess of permissible levels for DMF and ECH, respectively. Based on 77 personal samples, $22(28.6 \%)$ and three $(3.9 \%)$ respectively, exceeded permissible levels. We found no urine samples in excess of the BEI set by
ACGIH, due to the rapid excretion rate of NMF. The correlation between biological and environmental monitoring was considerably lower than that found in previous studies. Other factors influenced results, such as masks worn by workers in high-exposure areas, and the use of other metabolites to represent biological monitoring.

\section{References}

American Conference of Governmental Industrial Hygienists (ACGIH) (1999) Threshold limit values and biological exposure induces. ACGIH

Cheng TJ, Hwang SJ, Kuo HW, Lo JC, Chang Wu MJ (1999) Exposure to epichlorohydrin and dimethylformamide, glutathione $S$-transferases and sister chromatid exchange frequencies in peripheral lymphocytes. Arch Toxicol 73: 282-287

Fiorito A, Larese F, Molinari S, Zanin T (1997) Liver function alterations in synthetic leather workers exposed to dimethylformamide. Am J Ind Med 32: 255-260

Flemming LE, Shalat SL, Redlich CA (1990) Liver injury in workers exposed to dimethylformamide. Scand J Work Environ Health 16: 289-292

Imbriani M, Ghittori S, Longoni P, Cascone G, Gamba G (1986) Effects of dimethylformamide (DMF) on coagulation and platelet activity. Arch Environ Health 41: 90-93

Laskin S, Sellakumar AR, Kuschner M et al (1980) Carcinogenicity of epichlorohydrin in non-inbred Sprague-Dawley rats. J Nat Cancer Inst 65: 751-757

Mraz J, Nahova H (1992) Percutaneous absorption of $N, N$-dimethylformamide in humans. Int Arch Occup Environ Health 64: $257-262$

Ministry of Social Affairs (MSA) (1995) De Nationale MAC-lijst 1995 (in Dutch). SDU, The Hague

Pozzoli L, Cottica D, Ghittori S, Catenacci G (1981) Monitoring of occupational exposure to dimethylformamide by passive personal samplers and monomethylformamide urinary excretion. G Ital Med Lav 3: 161-163

Redlich CA, West AB, Flemming L, True LD, Cullen MR, Riely CA (1990) Clinical and pathological characteristics of hepatotoxicity associates with occupational exposure to dimethylformamide. Gastroenterology 99: 748-757

Rooij Ben M, Boogaard PJ, Commandeur Jan NM, Vermeulen Nico PE (1997) 3-Chloro-2-hydroxypropylmercapturic acid and $\alpha$-chlorohydrin as biomarkers of occupational exposure to epichlorohydrin. Environ Toxicol Pharmacol 3: 175-185

Sakai K, Kageyama H, Araki A, Yosida T, Kuribayashi I, Masuyama Y. (1995) Biological monitoring of workers exposed $N, N$-dimethylformamide by determination of the urinary metabolites, $N$-methylformamide and $N$-acetyl- $S$ - $(N$-methylcarbamoyl) cysteine. Int Arch Occup Environ Health 67: 125-129

SAS/STAT (1986) User's guide, release 6.04. SAS, Cary, NC

Sram RJ, Tomatis L, Clemmesen J, Bridges BA (1981) International Commission For Protection Against Environmental Mutagens And Carcinogens Publication No 7. An evaluation of the genetic toxicity of epichlorohydrin. Mutat Res 87: 299-319

Sram RJ, Landa L, Samkova I (1983) Effect of occupational exposure to epichlorohydrin on the frequency of chromosome aberrations in peripheral lymphocytes. Mutat Res 122: 59-64

Wang JD, Lai MY, Chen JS, Lin JM (1991) Dimethylformamideinduced liver damage among synthetic leather workers. Arch Environ Health 46: 161-166

Wester PW, Vander-Heijden CA, Bisschop A, Van Esch GJ (1985) Carcinogenicity study epichlorohydrin by gavage in rats. Toxicology 36: 325-339

Yonemoto J, Suzuki S (1980) Relation of exposure to dimethylformamide vapor and metabolite, methylformamide in urine of workers. Int Arch Occup Environ Health 46: 159-165 